\title{
Determinants of Glycosylated Haemaglobin among Adults with Type 2 Diabetes Mellitus
}

\author{
Melba Sheila D'souza ${ }^{1 *}$, Ramesh Venkatesaperumal ${ }^{2}$, Subrahmanya Nairy Karkada ${ }^{3}$ and Anandhi Amirtharaj ${ }^{2}$
}

${ }^{1}$ Sultan Qaboos University, Adult Health and Critical Care, College of Nursing, Oman

${ }^{2}$ Department of Adult Health and Critical Care, College of Nursing, Sultan Qaboos University, Oman

${ }^{3}$ Department of Business Studies and Management, Higher College of Technology, Sultan Qaboos University, Oman

\section{Abstract}

Purpose: The purpose of this study is to assess the determinants of demographic and clinical factors associated with $\mathrm{HbA} 1 \mathrm{C}$ levels among adults with type 2 diabetes mellitus (T2DM) in Muscat. Glycosylated Hemoglobin (HbA1C) is used as marker for long term blood glucose control in adults with type 2 diabetes mellitus.

Methods: A cross-sectional design was used. Simple random sampling was used to select 300 adults with T2DM in Oman in 2011. Ethical approval and hospital permission was completed from the Institutional Research and Ethics Committee. Informed consent was obtained from the participants. Chi-square and multiple logistic regression models with demographic and clinical characteristics as predictors of glycemic control $(\mathrm{HbA} 1 \mathrm{C})$ were used to analyze the results. Results: Nearly half percentage of the adults with T2DM had better or controlled $\mathrm{HbA} 1 \mathrm{C}(<7 \%)$ while the rest had poor or uncontrolled $\mathrm{HbA} 1 \mathrm{C}(>7 \%)$. Younger ages, females, higher education, non-tobacco users, short duration of diabetes, compliance with $\mathrm{OHA}$ and high waist-hip ratio predicted better control of $\mathrm{HbA1C}$.

Conclusions: Socio-demographic and clinical factors were consistently associated with glycemic control. Gender, education, perception of prevention of ADL, doctor-patient relationship, compliance with medications, and non-tobacco users were significant predictors of better glycemic controls among adults with T2DM. Relevance to clinical practice. Assessment of determinants of $\mathrm{HbA} 1 \mathrm{C}$ may assist in determining individualized goals and strategies, subsequently improve glycemic control and enhance self-care management.

Keywords: Diabetes mellitus; Type 2 diabetes mellitus; Glycosylated haemaglobin; Glycemic control; Diabetes nurse educator

\section{Introduction}

More than 180 million people worldwide have Diabetes Mellitus (DM) and there will be 366 million people with DM by the year 2030 $[1,2]$. Type 2 diabetes mellitus (T2DM) is expected to affect nearly $10 \%$ of the world's population by 2030 [3]. There is an increased prevalence of T2DM worldwide, affecting more than $8 \%$ of the global adult population with increased numbers between $40-59$ years. There is an increasing prevalence of DM from $9.6 \%$ (1991) to $11.6 \%$ (2000) to $12.3 \%$ (2008) to $13.4 \%$ (2010) in Oman [4-7]. The prevalence of DM among ages 30-64 years was $16 \%$ in Omani men and $15.4 \%$ in women $(\mathrm{p}<0.325)(\mathrm{N}=5838)[6]$. Hence the prevalence and incidence of T2DM is predicted to increase by approximately $45 \%$ over a decade [7].

Diabetes mellitus has a significant impact on the lives of individuals, their families, and the health care system in Oman. More than $14 \%$ of Oman populations with T2DM had diabetic retinopathy, 27\% had microalbuminuria and $50 \%$ had amputations in Oman compared to $11.6 \%$ of Saudis and $6.7 \%$ of Indians with retinopathy [8,9]. Among 7442 Type $1 \mathrm{DM}$ and T2DM patients, only $22.8 \%$ had good glycemic control influenced by control of blood pressure, blood glucose and body mass index, while $77.2 \%$ did not have a good glycemic control $[10,11]$. Among 5000 adults with DM, it was found that smoking, insulin and waist-hip ratio influenced the control of HbA1C $[12,4]$. Studies have shown that lowering glycosylated hemaglobin or glycated heamaglobin ( $\mathrm{HbA1C}$ ) to below or around $7 \%$ soon after the diagnosis of diabetes has reduced microvascular and macrovascular complications than people with $\mathrm{HbA1C}$ at higher levels [13-15]. Hence HbA1C is widely used as a marker of evaluation of long term glycemic control in diabetic patients and predicts risks for the development and/ or progression of diabetic complications $[16,17]$. In our study the predictors influencing good glycemic control among adults with T2DM was explored to recommend best practices for diabetes care in Oman.

\section{Aim}

Assess the determinants associated with glycemic control or glycosylated hemaglobin among adults with T2DM in Muscat.

\section{Design and Methodology \\ Design}

A cross-sectional research design was used to assess the determinants of glycemic control among adults with T2DM in Muscat.

\section{Sample}

All adults with T2DM attending public hospitals at Muscat were included in the target population. The sample size was determined using $G^{\star}$ Power software with the intention to use multiple logistic regression (MLR) analysis [18]. The sample size was calculated at a power of 0.9 with a moderate effect size of 0.15 using 14 predictors (independent variables including socio-demographic and clinical characteristics) with alpha $=0.05, \mathrm{SD}$ of $1 \%$ on two-tailed testing with

*Corresponding author: Melba Sheila D'souza, RNRM, MSN, MPhil, PhD Sultan Qaboos University, Adult Health and Critical Care, College of Nursing PB 66, Al Khoud, Muscat, Muscat 123, Oman, Tel: 0096898137770; E-mail: melba123@rediffmail.com

Received May 02, 2013; Accepted May 28, 2013; Published June 02, 2013

Citation: D'souza MS, Venkatesaperumal R, Karkada SN, Amirtharaj A (2013) Determinants of Glycosylated Haemaglobin among Adults with Type 2 Diabetes Mellitus. J Diabetes Metab 4: 265. doi:10.4172/2155-6156.1000265

Copyright: (C) 2013 D'souza MS, et al. This is an open-access article distributed under the terms of the Creative Commons Attribution License, which permits unrestricted use, distribution, and reproduction in any medium, provided the original author and source are credited. 
95\% power. The effect size was computed with an expected difference (change in $\mathrm{HbA1C}$ of $0.07 \%$ ) between the controlled and uncontrolled HbA1C groups (metric/variable) as clinically significant [19,20]. A sample size of 270 was needed with these input parameters. Thus, 300 adults with T2DM were recruited, assuming a $10 \%$ attrition rate.

Inclusion criteria included adults aged above 18 years diagnosed with T2DM as recommended by the American Diabetes Association's Guidelines [13,21] since 2 years. Adults, who were able to understand, communicate or converse in Arabic or English language. Exclusion criteria included participants will be excluded, if they are undiagnosed with T2DM, have known T1DM or have cognitive impairment or physical disability.

\section{Measurements}

Clinical or physiological measurements: For this study, the HbA1C value will be categorized into controlled (good glycemic control) if $\mathrm{HbAlC}$ values are $\leq 7 \%$ and uncontrolled (poor glycemic control) if $\mathrm{HbA} 1 \mathrm{C}$ values are $\geq 7 \%[21,13]$. Hypertension was defined as a systolic blood pressure $\geq 140 \mathrm{mmHg}$ and/or diastolic blood pressure $\geq 90 \mathrm{mmHg}$ or being on antihypertensive medications [22]. Body mass index (calculated as weight in kilograms divided by the square of height in meters $\left.\left[\mathrm{Kg} / \mathrm{m}^{2}\right]\right)$ was categorized as underweight $(\leq 18.5 \mathrm{Kg} /$ $\mathrm{m}^{2}$ ), normal (BMI $\left.18 \leq 25 \mathrm{Kg} / \mathrm{m}^{2}\right)$, overweight $\left(\right.$ BMI $\left.25 \leq 30 \mathrm{Kg} / \mathrm{m}^{2}\right)$ and obese $\left(\mathrm{BMI} \geq 30 \mathrm{Kg} / \mathrm{m}^{2}\right)$. Waist circumference $\geq 94 \mathrm{~cm}$ (39 inches) for males and $\geq 80 \mathrm{~cm}$ ( 35 inches) for females was considered as a risk factor for DM. Waist-hip ratio $\geq 0.90$ for males and $\geq 0.85$ for females is a risk factor of increased $\mathrm{HbA1C}$ [23].

Socio-demographic characteristics survey (ten items) was used to describe the characteristics among adults with T2DM was developed by the investigators based on the literature review and study instruments. It contains questions about age, gender, formal education, smoking, duration of T2DM diagnosis, previous formal diabetes education etc.

\section{Ethical Considerations}

Ethical approval was provided by the Ethics and Research Committee, College of Nursing and Sultan Qaboos University Hospital, SQU. Written consent was obtained from each participant, after providing a written letter explaining, the purposes of the study, the risks and benefits of participation, instructions and study questionnaires. Participants were assured of voluntary participation and free will to withdraw from the study at any time without any consequences. Anonymity was maintained between the investigator and the participant. All informed consents were stored and locked separately from data files in cabinets. Confidentiality was maintained by assigning code numbers to the data files.

\section{Data analysis}

All data were checked for high quality, directly pertinent to the main aims of the study, collected in a systematic and closely monitored manner. Data were entered into Statistical Packages for Social Sciences (SPSS) version 20 for comparing, analysis and auditing for accuracy. Data were screened for missing values, logical inconsistencies and extreme values. A confidence value of $95 \%$ and probability of $<0.05$ was considered statistically significant for all tests. Descriptive summaries of sample characteristics were used to describe the participants. Multivariate logistic regression (MLR) was used to assess the determinants associated with glycemic control. Standardized tools on demographic and clinical characteristics of diabetes supported by comprehensive review of literature were used to choose the variables in the study and are used as determinants of HbA1C. All these variables are used in the logistic regression model. Multi-collinearity is checked before the data analysis and is taken care of during the data analysis to avoid influence of highly correlated pairs of variables.

\section{Results}

Among 300 adults with T2DM, 138 (46\%) had controlled HbA1C $(\leq 7 \%)$ compared to $162(54 \%)$ adults with uncontrolled HbA1C $(>7 \%)$.

\section{Socio-demographic characteristics and association with HbA1C}

One-third of the adults with T2DM (34\%) were aged $40-49$ years, of which half of the percentage had controlled HbA1C <7\% (50.5\%) (Table 1). Adults above 60 years (19\%) had HbA1C in the controlled $(44.8 \%)$ and uncontrolled group respectively (58\%). 52\% of the adults with T2DM were females, of which $53.5 \%$ of them had controlled HbA1C compared to the men (48\%) in the controlled group (37.8\%). More than one-third of the adults with T2DM had primary education (39\%), of which $47.9 \%$ had controlled HbA1C compared to $54.3 \%$ of adults with high school education (31\%). $45 \%$ of the adults with T2DM were tobacco users, of which $39.7 \%$ had controlled $\mathrm{HbA1C}$ compared to uncontrolled HbA1C (60.3\%). Non-tobacco smokers (54.7\%) showed controlled (28\%) compared to uncontrolled (49.1\%) HbA1C. Most of the adults (74\%) had poor knowledge of diabetes and its management, of which $43.2 \%$ had controlled HbA1C compared to those with average (51.4\%) and excellent knowledge (56.1\%). Adults with T2DM who were younger, females, higher education and non-tobacco users showed better or controlled $\mathrm{HbA1C}$ and were significantly associated with $\mathrm{HbA1C}(\mathrm{p}<0.05)$. Adults who reported diabetes mostly prevented ADL, had moderate ability to manage diabetes positively, had mostly comfortable doctor-patient relationship and had higher knowledge of diabetes and its management had better or controlled $\mathrm{HbA} 1 \mathrm{C}$ and were significantly associated with $\mathrm{HbA1C}(\mathrm{p}<0.05)$, except for ability to manage DM positively.

\section{Clinical-physiological characteristics and association with HbA1C}

Nearly half percentage of the adults (48\%) who lived with T2DM for $10-19$ years, of which $47.2 \%$ of them had controlled HbAlC compared to those with less than 10 years ( $50.9 \%$ of $37 \%)$. More adults (62\%) were exposed to diabetes education program (DEP), of which $45.4 \%$ had controlled HbA1C compared to uncontrolled (54.6\%). Most of the adults $(75 \%)$ were on oral hypoglycemic agents (OHA/tablets), of which $48.7 \%$ had controlled HbA1C. Among adults on OHA and insulin (25\%), only $9.7 \%$ had controlled HbA1C. More adults $(67 \%)$ with T2DM showed healthy body mass index (BMI), of which $43.1 \%$ showed controlled HbA1C. $53.3 \%$ of the adults overweight $(30 \%)$ showed controlled HbA1C. Majority of the adults (84\%) with T2DM were hypertensives, of which $45.1 \%$ had controlled HbA1C. Among $16 \%$ of the normotensives, $51.1 \%$ of them had controlled HbA1C. Among adults with T2DM with high waist circumference (WC) (71\%), controlled (43.4\%) vs uncontrolled (56.6\%) HbA1C were higher compared to those adults $(29 \%)$ with low waist circumference in control (52.3\%) and without control (47.7\%). Half percentage of the adults with T2DM had low waist-hip ratio (WHR) (48.7\%), of which $52.7 \%$ had controlled HbA1C compared to $39.6 \%$ of those (51.3\%) with high WHR. Adults with higher BMI or overweight, normotensives, low waist circumference and low waist-hip ratio showed more controlled HbA1C. Adults with less duration of diabetes, exposure to DEP and on known OHA had better or controlled HbA1C. Adults with short 
Citation: D'souza MS, Venkatesaperumal R, Karkada SN, Amirtharaj A (2013) Determinants of Glycosylated Haemaglobin among Adults with Type 2 Diabetes Mellitus. J Diabetes Metab 4: 265. doi:10.4172/2155-6156.1000265

Page 3 of 6

duration of diagnosis of diabetes, on known OHA and low waist-hip ratio were significantly associated with $\mathrm{HbA1C}(\mathrm{p}<0.05)$ (Table 2$)$.

\section{Determinants of HbA1C}

All the variables or predictors (Odds ratio $=1.0$ as reference category) of glycemic control (HbA1C) were included in a MLR model to estimate their independent effects on glycemic control among adults with T2DM (Table 3). After controlling for all other covariates, the Odds ratio (OR) of poor glycemic control was increased with the use of OHA and insulin (OR=1.909, 95\% CI: 1.04, 3.50) compared to those on OHA alone. There is an inverse relationship between OR of good glycemic control and tobaccos users (OR=1.775, 95\% CI: 1.01, 3.11) compared to non-tobacco users. OR of good glycemic control was decreased among males (OR=0.527, 95\% CI: 0.32, 0.88) compared to females. Higher education $(\mathrm{OR}=1.328,95 \% \mathrm{CI}: 0.96,1.84)$ was inversely proportional to good glycemic control compared to low education. Stronger perceptions of diabetes mostly preventing ADL (OR $=0.851$, $95 \%$ CI: $0.70,1.03$ ) was associated with poor glycemic control compared to those with better ADL with DM. Mostly comfortable doctor-patient relationship (OR=0.721, 95\% CI: $0.55,0.95)$ was associated with poor glycemic control compared to moderately comfortable doctor-patient relationship. Lower BMI, low blood pressure and low waist-hip ratio was inversely proportional to good glycemic control. These findings show that adults who were younger, females, using OHA and insulin, non-tobacco users, higher education, stronger perceptions of DM preventing ADL and mostly comfortable doctor-patient relationship were significant independent predictors of controlled HbA1C.

\section{Discussion and Conclusion}

The findings showed half percentage of the adults with T2DM

\begin{tabular}{|c|c|c|c|c|c|c|c|c|}
\hline Characteristics & Categories & HbA1C $\leq 7 \%$ & $\%$ & HbA1C $>7 \%$ & $\%$ & $\mathbf{N}$ & Chi square & $P$ value \\
\hline \multirow{4}{*}{ Age (years) } & $30-39$ & 24.0 & 51.1 & 23.0 & 48.9 & 47.0 & \multirow{4}{*}{3.099} & \multirow{4}{*}{0.377} \\
\hline & $40-49$ & 52.0 & 50.5 & 51.0 & 49.5 & 103.0 & & \\
\hline & $50-59$ & 36.0 & 39.1 & 56.0 & 60.9 & 92.0 & & \\
\hline & $60 \&$ above & 26.0 & 44.8 & 32.0 & 55.2 & 58.0 & & \\
\hline \multirow{2}{*}{ Gender } & Male & 54.0 & 37.8 & 89.0 & 62.2 & 143.0 & \multirow{2}{*}{7.465} & \multirow{2}{*}{$0.006^{*}$} \\
\hline & Female & 84.0 & 53.5 & 73.0 & 46.5 & 157.0 & & \\
\hline \multirow{3}{*}{ Education } & Upto 8th & 56.0 & 47.9 & 61.0 & 52.1 & 117.0 & \multirow{3}{*}{12.52} & \multirow{3}{*}{$0.006^{*}$} \\
\hline & High school & 51.0 & 54.3 & 43.0 & 45.7 & 94.0 & & \\
\hline & Diploma or Technical training & 31.0 & 10.3 & 58.0 & 67.4 & 89.0 & & \\
\hline \multirow{2}{*}{ Smoking } & No & 84.0 & 28.0 & 80.0 & 49.1 & 164.0 & \multirow{2}{*}{3.756} & \multirow{2}{*}{$0.05^{\star}$} \\
\hline & Yes & 54.0 & 39.7 & 82.0 & 60.3 & 136.0 & & \\
\hline \multirow{3}{*}{ DM prevents activities of daily living (ADL) } & Never & 43.0 & 39.8 & 65.0 & 60.2 & 108.0 & \multirow{3}{*}{22.086} & \multirow{3}{*}{$0.001^{*}$} \\
\hline & Moderately & 74.0 & 47.4 & 82.0 & 52.6 & 156.0 & & \\
\hline & Mostly & 21.0 & 58.3 & 15.0 & 41.7 & 36.0 & & \\
\hline \multirow{2}{*}{ Ability to manage DM positively } & Moderate ability & 95.0 & 31.7 & 97.0 & 32.3 & 192.0 & \multirow{2}{*}{4.151} & \multirow{2}{*}{0.246} \\
\hline & Good ability & 43.0 & 14.3 & 65.0 & 21.7 & 108.0 & & \\
\hline \multirow{2}{*}{ Doctor-patient relationship } & Moderate & 108.0 & 45.6 & 129.0 & 54.4 & 237.0 & \multirow{2}{*}{12.139} & \multirow{2}{*}{$0.016^{*}$} \\
\hline & Mostly comfortable & 30.0 & 47.6 & 33.0 & 52.4 & 63.0 & & \\
\hline \multirow{3}{*}{ Knowledge of DM and management } & Poor & 96.0 & 43.2 & 126.0 & 56.8 & 222.0 & \multirow{3}{*}{6.008} & \multirow{3}{*}{0.422} \\
\hline & Average & 19.0 & 51.4 & 18.0 & 48.6 & 37.0 & & \\
\hline & Excellent & 23.0 & 56.1 & 18.0 & 43.9 & 41.0 & & \\
\hline
\end{tabular}

${ }^{*} p<0.05,{ }^{* *} p<0.10$. HbA1C: Glycosylated Haemaglobin; DM: Diabetes Mellitus

Table 1: Demographic characteristics among adults with T2DM N=300

\begin{tabular}{|c|c|c|c|c|c|c|c|c|}
\hline Clinical characteristics & Categories & $\mathrm{HbA} 1 \mathrm{C} \leq 7 \%$ & $\%$ & HbA1C >7\% & $\%$ & $\mathbf{N}$ & Chi square & $P$ value \\
\hline \multirow{3}{*}{ Duration of DM years } & $0-9$ & 57.0 & 50.9 & 55.0 & 49.1 & 112.0 & \multirow{3}{*}{5.962} & \multirow{3}{*}{$0.05^{\star}$} \\
\hline & $10-19$ & 68.0 & 47.2 & 76.0 & 52.8 & 144.0 & & \\
\hline & $20 \&$ above & 13.0 & 29.5 & 31.0 & 70.5 & 44.0 & & \\
\hline \multirow{2}{*}{ Diabetes education program } & No & 54.0 & 47.0 & 61.0 & 53.0 & 115.0 & \multirow{2}{*}{0.069} & \multirow{2}{*}{0.793} \\
\hline & Yes & 84.0 & 45.4 & 101.0 & 54.6 & 185.0 & & \\
\hline \multirow{2}{*}{ Medications } & $\mathrm{OHA}$ & 109.0 & 48.7 & 107.0 & 51.3 & 216.0 & \multirow{2}{*}{6.242} & \multirow{2}{*}{$0.044^{*}$} \\
\hline & $\mathrm{OHA}$ and insulin & 29.0 & 9.7 & 55.0 & 18.3 & 84.0 & & \\
\hline \multirow{3}{*}{ Body mass index } & $<18.5$ - Underweight & 3.0 & 37.5 & 5.0 & 62.5 & 8.0 & \multirow{3}{*}{2.88} & \multirow{3}{*}{0.237} \\
\hline & $18.5-24.9$ - Healthy weight & 87.0 & 43.1 & 115.0 & 56.9 & 202.0 & & \\
\hline & 25 - 29.9 - Overweight & 48.0 & 53.3 & 42.0 & 46.7 & 90.0 & & \\
\hline \multirow{2}{*}{ Blood pressure $(\mathrm{mmHg})$} & $\leq 140 / 90$ & 24.0 & 51.1 & 23.0 & 48.9 & 47.0 & \multirow{2}{*}{0.575} & \multirow{2}{*}{0.274} \\
\hline & $>140 / 90$ & 114.0 & 45.1 & 139.0 & 54.9 & 253.0 & & \\
\hline \multirow{2}{*}{ Waist circumference (inches) } & $<39 "(\mathrm{M})$ or $35^{\prime \prime}(\mathrm{F})$ & 46.0 & 52.3 & 42.0 & 47.7 & 88.0 & \multirow{2}{*}{1.973} & \multirow{2}{*}{0.16} \\
\hline & $>39 "(\mathrm{M})$ or $35^{\prime \prime}(\mathrm{F})$ & 92.0 & 43.4 & 120.0 & 56.6 & 212.0 & & \\
\hline \multirow{2}{*}{ Waist-hip ratio } & $<0.90(\mathrm{M})$ or $0.85(\mathrm{~F})$ & 77.0 & 52.7 & 69.0 & 47.3 & 146.0 & \multirow{2}{*}{2.56} & \multirow{2}{*}{$0.086^{* *}$} \\
\hline & $>0.90(\mathrm{M})$ or $0.85(\mathrm{~F})$ & 61.0 & 39.6 & 93.0 & 60.4 & 154.0 & & \\
\hline
\end{tabular}

${ }^{*} \mathrm{p}<0.05,{ }^{* *} \mathrm{p}<0.10 \mathrm{HbA} 1 \mathrm{C}$ - glycosylated haemaglobin, DM- Diabetes Mellitus, OHA: Oral Hypoglycemic Agents

Table 2: Clinical characteristics among adults with $T 2 D M N=300$. 


\begin{tabular}{|c|c|c|c|}
\hline Determinants/ Predictors & Odds ratio (OR) & 95\% Confidence interval $(\mathrm{Cl})$ & $p$ value \\
\hline Age (years) & 1.115 & $0.82,1.52$ & 0.49 \\
\hline Gender & 0.527 & $0.32,0.88$ & $0.014^{*}$ \\
\hline Education & 1.328 & $0.96,1.84$ & $0.089^{* *}$ \\
\hline Smoking & 1.775 & $1.01,3.11$ & $0.045^{*}$ \\
\hline DM prevents normal daily activities & 0.851 & $0.70,1.03$ & $0.095^{\star *}$ \\
\hline Ability to manage DM positively & 1.124 & $0.75,1.68$ & 0.566 \\
\hline Doctor-patient relationship & 0.721 & $0.55,0.95$ & $0.021^{*}$ \\
\hline Knowledge of DM and management & 1.101 & $0.90,1.34$ & 0.339 \\
\hline Duration of DM years & 1.239 & $0.82,1.87$ & 0.306 \\
\hline DM education program & 1.036 & $0.59,1.83$ & 0.903 \\
\hline Medications & 1.909 & $1.04,3.50$ & $0.037^{*}$ \\
\hline Body mass index & 0.735 & $0.45,1.20$ & 0.222 \\
\hline Blood pressure $(\mathrm{mmHg})$ & 0.981 & $0.48,2.00$ & 0.959 \\
\hline Waist-Hip Ratio & 0.568 & $0.19,1.72$ & 0.317 \\
\hline Constant & 6.616 & & 0.3 \\
\hline
\end{tabular}

${ }^{*} p<0.05,{ }^{* *} p<0.10 . O R=1$, reference category

Table 3: Odds ratio of glycaemic control in multivariate logistic regression used to predict $\mathrm{HbA} 1 \mathrm{C}$ among adults with T2DM.

were far from the ADA goals HbA1C $(>7 \%)$ and have not achieved the targeted values. In another study $77.2 \%$ have poor glycemic control $(\mathrm{N}=7442)$ [10]. Higher $\mathrm{HbA1C}$ values may be related to rapid changes in lifestyles, urbanization, mobility and shift from rural labor-intensive jobs to employment in less strenuous office-based or industrial jobs leading to increased biological and behavioral risk factors [24].

The glycemic control was poorer among middle-aged adults with T2DM. There is an inverse relation between mean $\mathrm{HbA} 1 \mathrm{C}$ and various age groups and those with $\geq 5$ years of diabetes had higher mean HbA1C levels compared to those who had diabetes for $<5$ years [24]. Age influences early glucose tolerance over which individuals have no control [25]. In this study females showed more controlled HbA1C compared to the men. Women who have better glycemic control had significantly lower BMI, more support and confidence in living with diabetes (22\% of the variance) [26]. In this study adults with higher education showed more controlled $\mathrm{HbA1C}$. Younger age participants who were educated were more likely to follow self-care diabetes management. Non-tobacco users showed more controlled HbAlC compared to tobacco users. In another study heavy smokers and number of cigarettes used per day ( $>20$ cigarette/day) increased among younger male diabetics $(73.1 \%)$ compared to the older diabetics $(67 \%$; $\mathrm{p}<0.05)$ [27]. Smoking also significantly influences glucose control, if the individuals who smoked do not adhere to self-care management [25]. This shows younger ages, females, higher education, non-tobacco users, exposure to diabetes education program were associated with better glycemic control over which individuals have no control.

In this study increased BMI among adults with T2DM reflected better or controlled $\mathrm{HbA1C}$. Obesity and overweight are significantly more prevalent among patients aged 40-59 years compared to those $<40$ or $\geq 60$ years [24]. $83 \%$ of the T2DM $(\mathrm{N}=334)$ have poorly controlled Fasting Blood Sugar levels (FBS) and poor BMI (36.8\%) with female predominance and $<55$ years [28]. One-fifth of the adult Omani population is obese (of which $36.8 \%$ are diabetics) $[29,30]$. Low education among Omani adults with T2DM are more likely to be centrally obese than those with a secondary or university education [12]. This shows obesity increases with low education. A 4-kg weight loss significantly reduces the risk of glycaemic decline early in the course of diabetes [25]. Hypertensives (60\%) and obesity (26.4\%) among adults with T2DM led to poorly controlled HbA1C (67\%) $[30,31,11]$. Those with poor glycemic control are more likely to have hypertension than those well-controlled [25]. This shows overweight adults with high $\mathrm{HbA1C}$ are younger, motivated and educated to lose weight to significantly improve their early glycaemic control.

In this study low waist circumference (WC) and low waist-hip ratio (WHR) reflected better HbA1C. In another study the mean WC and hip circumference $(\mathrm{HC})$ among $52 \%$ Omani males $(89.7 \mathrm{~cm}$ and $96.5 \mathrm{~cm})$ and $48 \%$ females $(88.7 \mathrm{~cm}$ vs $99 \mathrm{~cm}$ ) respectively was high. More than one third of the Omani population have excess abdominal fat (i.e. centrally obese) while $64 \%$ have an abnormal/high WHR. Majority of the Omanis who are illiterate have a high WHR (78\%), while 56\% of those with university education have high WHR [12]. This shows females and those with low education are more liable for abdominal fat than males in the study.

In this study adults who reported that diabetes mostly prevented $\mathrm{ADL}$ and with moderate ability to manage diabetes had better $\mathrm{HbA1C}$ Significant correlates of self-management ( $52 \%$ of the variance) includes older age, better integration of diabetes into daily life, less diabetesrelated distress, more support, confidence in living with diabetes, and better mental health functioning [26]. Almost half percentage of T2DM received care from a general practitioner while others were seen by a specialist [24]. $62 \%$ of the T2DM received advice from doctors regarding care during fasting/ Ramadhan [32]. There was poor interaction between Omani adults with T2DM and doctors and nurses [33]. This shows control of their HbA1C was similar among adults with moderate or mostly comfortable doctor-patient relationship due to increased diabetes management program, support and access to free health care facilities at all levels.

In this study adults with average knowledge of diabetes and its management had better $\mathrm{HbA1C}$ scores. Here younger Omani diabetics adhered to follow-ups and appointments compared to older adults. Adults adhered to monitoring weight (53\%), self-blood glucose monitoring $(59 \%)$, monitoring and physical examination and ECG (82\%). $30 \%$ of the subjects reported care from a diabetes educator, $44 \%$ visited the dietitian while only $26.8 \%$ reported non-adherence to diet [24]. Self-management education leads to improved glycaemia at immediate contact time [34]. Patients who attend regular diabetes education programs showed improved diabetes control over low attenders.

In this study adults with short duration of diagnosis of T2DM and on oral hypoglycemic agents (OHA) and insulin had better HbA1C. Majority of patients were on OHA (79\%), diet (8.8\%) and insulin 
(14.0\%) [24]. Participants with poor glycemic control were more likely to require OHA and insulin $(\mathrm{p}=0.044)$ [25]. This shows participants with poor glycemic control are at higher risk of commencing insulin after the initial diagnosis.

In our study younger age group, females, controlled blood pressure, and low body mass index had better glycemic control. Other studies show that there was a significant association between mean $\mathrm{HbAlC}$ and age groups, $\geq 5$ years of diabetes, on OHA, BMI (overweight or obesity) and non-tobacco users was significant ( $\mathrm{p}=0.001$ ). Patients with normal BMI, on diet or insulin and with health care index score of $<5$ did not show significant trend in the mean HbAlC towards younger age groups $(p>0.05)$ [24]. The diabetic males who are tobacco users, used more number of smoked cigarettes/day, and longer duration of smoking had longer duration of diabetes, higher diastolic blood pressure, and higher $\mathrm{HbAlC}$ and FBS significantly higher compared to younger diabetics $[4,27]$.

In our study odds ratio of good glycemic control was increased with increasing compliance to OHA, non-tobaccos users, females and education. Gender, education, perception of prevention of ADL, doctorpatient relationship, compliance with medications, and non-tobacco users predicted better control of glycosylated hemoglobin among adults with T2DM. The OR of good glycemic control was significantly increased with increase in females, reduced with increasing duration of diabetes, overweight and obesity, increasing age, longer duration of diabetes ( $\geq 5$ years) and those on oral or insulin treatment was inversely related to good glycemic control [24]. Inverse relationship of good glycemic control was found with age among Omanis with T2DM [35]. The risk of microvascular and macrovascular complications is strongly associated with the level of glycemia [36] and quality of life [37].

\section{Clinical relevance for diabetes nurse educators}

Younger age, females, higher education, non-tobacco users, diabetes mostly prevented normal ADL, moderate ability to manage positively, mostly comfortable doctor-patient relationship and higher knowledge of diabetes and management of T2DM predicted increased achievement of controlled HbA1C. Short duration of diabetes, compliance with OHA and low waist-hip ratio predicted better control of HbA1C. Gender, education, perception of prevention of ADL, doctor-patient relationship, compliance with medications, and nontobacco users were predicted to impact glycemic control among adults with T2DM in Muscat. Knowledge of determinants influencing early glycemic control can be used by diabetes nurses educators (DNE) to provide targeted interventions to those at greatest risk of short- or long term complications. These have direct impact on the economic state of patients and families. These results can be utilized by DNE to emphasize management, motivation and reinforcement in adhering to self-care activities and efficacy in self-management of diabetes. The role of the DNE in ongoing assessment, continuous monitoring, close supervision, reinforcement of education and prevention of complications among adults with T2DM is important. A supervised culturally tailored individualized self-management by the DNE is important to achieve tight or good control of T2DM among these adults in Muscat.

\section{Limitations}

The strength of this study is the consistency of the results with research studies related to $\mathrm{HbA} 1 \mathrm{C}$ among adults with T2DM in Oman. This study is limited by the cross-sectional design and is not causal or effect study or measure of temporal changes. Many factors that can influence $\mathrm{HbAlC}$ levels (e.g. co-morbid conditions, physical activity index, genetically inherited hemoglobinopathies, income, marital status, employment, health literacy, social support system) have not been studied.

\section{References}

1. Wild S, Roglic G, Green A, Sicree R, King H (2004) Global prevalence of diabetes: estimates for the year 2000 and projections for 2030. Diabetes Care 27: 1047-1053

2. World Health Organization. (2011) WHO Global InfoBase.

3. International Diabetes Federation (2011) Diabetes Atlas ( $5^{\text {th }}$ edn)

4. Asfour MG, Lambourne A, Soliman A, Al-Behlani S, Al-Asfoor D, et al. (1995) High prevalence of diabetes mellitus and impaired glucose tolerance in the Sultanate of Oman: results of the 1991 national survey. Diabet Med 12: 1122 1125.

5. Asfour MG, Samantray SK, Dua A, King H (1991) Diabetes mellitus in the sultanate of Oman. Diabet Med 8: 76-80.

6. Al-Lawati JA, Al Riyami AM, Mohammed AJ, Jousilahti $P$ (2002) Increasing prevalence of diabetes mellitus in Oman. Diabet Med 19: 954-957.

7. Ministry of Health. (2010) Annual Health Report: MOH Publications: Sultanate of Oman.

8. Ministry of Health (2008) World Health Survey: Oman. Department of Research Directorate General of Planning, Ministry of Health publications.

9. Al-Futaisi A, Al-Zakwani I, Almahrezi A, Al-Hajri R, Al-Hashmi L, et al. (2006) Prevalence and predictors of microalbuminuria in patients with type 2 diabetes mellitus: a cross-sectional observational study in Oman. Diabetes Res Clin Pract 72: 212-215.

10. Venugopal S, Kunju R, Al Harthy S, Al Zadjali N (2008) Hemoglobin A1c in Muscat, Oman - A 3 year study. Oman Med J 23: 170-172.

11. Al-Moosa S, Allin S, Jemiai N, Al-Lawati J, Mossialos E (2006) Diabetes and urbanization in the Omani population: an analysis of national survey data Popul Health Metr 4: 5

12. Al Riyami A, Elaty MA, Morsi M, Al Kharusi H, Al Shukaily W, et al. (2012) Oman world health survey: part 1 - methodology, sociodemographic profile and epidemiology of non-communicable diseases in oman. Oman Med J 27: 425443

13. American Diabetes Association (2013) American Diabetes Association: Clinical practice recommendations. Diabetes Care 30: S1-S103.

14. De Fronzo RA, Ferrannini E, Keen H, Zimmet $P$ (2004) International Textbook of Diabetes Mellitus ( $3^{\text {rd }}$ Edn) 2.

15. (1997) U.K. Prospective Diabetes Study 27. Plasma lipids and lipoproteins at diagnosis of NIDDM by age and sex. Diabetes Care 20: 1683-1687.

16. Karl J, Burns G, Engel WD, Finke A, Kratzer M, et al. (1993) Development and standardization of a new immunoturbidimetric assay HbA1C Assay. Klin Lab 39: 991-996.

17. Calisti L, Tognetti S (2005) Measure of glycosylated hemoglobin. Acta Biomed 76 Suppl 3: 59-62.

18. Faul F, Erdfelder E, Lang AG, Buchner A (2007) G*Power 3: a flexible statistical power analysis program for the social, behavioral, and biomedical sciences. Behav Res Methods 39: 175-191.

19. Amsberg S, Anderbro T, Wredling R, Lisspers J, Lins PE, et al. (2009) A cognitive behavior therapy-based intervention among poorly controlled adult type 1 diabetes patients--a randomized controlled trial. Patient Educ Couns 77: $72-80$

20. Van Der Ven NC, Weinger $\mathrm{K}$, Yi J, Pouwer $\mathrm{F}$, Adèr $\mathrm{H}$, et al (2003) The confidence in diabetes self-care scale: psychometric properties of a new measure of diabetes-specific self-efficacy in Dutch and US patients with type 1 diabetes. Diabetes Care 26: 713-718.

21. International Diabetes Federation (2013) Diabetes Atlas. 4th ed. Brussels, Belguim.

22. Chobanian AV, Bakris GL, Black HR, Cushman WC, Green LA, et al. (2003) Seventh report of the Joint National Committee on Prevention, Detection, Evaluation, and Treatment of High Blood Pressure. Hypertension 42: 12061252. 
Citation: D'souza MS, Venkatesaperumal R, Karkada SN, Amirtharaj A (2013) Determinants of Glycosylated Haemaglobin among Adults with Type 2 Diabetes Mellitus. J Diabetes Metab 4: 265. doi:10.4172/2155-6156.1000265

Page 6 of 6

23. Alberti KG, Zimmet P, Shaw J (2006) Metabolic syndrome--a new world-wide definition. A Consensus Statement from the International Diabetes Federation. Diabet Med 23: 469-480.

24. Al-Lawati JA, Mabry R, Mohammed AJ (2008) Addressing the threat of chronic diseases in Oman. Prev Chronic Dis 5: A99.

25. Kellow NJ, Savige GS, Khalil H (2011) Predictors of poor glycaemic control during the initial five years post-diagnosis in rural adults with type 2 diabetes. Aust J Rural Health 19: 267-274.

26. Whittemore R, D'Eramo Melkus G, Grey M (2005) Metabolic control, selfmanagement and psychosocial adjustment in women with type 2 diabetes. $J$ Clin Nurs 14: 195-203.

27. Al-Mukhtar SB, Fadhil NN, Hanna BE (2012) General and gender characteristics of type 2 diabetes mellitus among the younger and older age groups. Oman Med J 27: 375-382.

28. Patel P, Mirakhur A, El-Magd KM, El-Matty AN, Al-Ghafri D (2007) Type 2 Diabetes and its Characteristics during Ramadan in Dhahira Region, Oman. Oman Med J 22: 16-23.

29. Al-Lawati JA, Jousilahti PJ (2004) Prevalence and 10-year secular trend of obesity in Oman. Saudi Med J 25: 346-351.

30. Al-Riyami AA, Afifi MM (2003) Accuracy of self-reporting of diabetes mellitus and hypertension and its determinants among Omani adults. Saudi Med J 24: 1025-1026.
31. Gilliland SS, Carter JS, Skipper B, Acton KJ (2002) HbA(1c) levels among American Indian/Alaska Native adults. Diabetes Care 25: 2178-2183.

32. Salti I, Bénard E, Detournay B, Bianchi-Biscay M, Le Brigand C, et al. (2004) A population-based study of diabetes and its characteristics during the fasting month of Ramadan in 13 countries: results of the epidemiology of diabetes and Ramadan 1422/2001 (EPIDIAR) study. Diabetes Care 27: 2306-2311.

33. Abdulhadi N, Al-Shafaee MA, Ostenson CG, Vernby A, Wahlström R (2006) Quality of interaction between primary health-care providers and patients with type 2 diabetes in Muscat, Oman: an observational study. BMC Fam Pract 7 : 72

34. Norris SL, Lau J, Smith SJ, Schmid CH, Engelgau MM (2002) Self-management education for adults with type 2 diabetes: a meta-analysis of the effect on glycemic control. Diabetes Care 25: 1159-1171.

35. El-Kebbi IM, Cook CB, Ziemer DC, Miller CD, Gallina DL, et al. (2003) Association of younger age with poor glycemic control and obesity in urban african americans with type 2 diabetes. Arch Intern Med 163: 69-75.

36. Stratton IM, Adler AI, Neil HA, Matthews DR, Manley SE, et al. (2000) Association of glycaemia with macrovascular and microvascular complications of type 2 diabetes (UKPDS 35): prospective observational study. BMJ 321 : 405-412.

37. Coffey JT, Brandle M, Zhou H, Marriott D, Burke R, et al. (2002) Valuing healthrelated quality of life in diabetes. Diabetes Care 25: 2238-2243. 